\title{
Lorne H. Blackbourne: Advanced surgical recall third edition
}

\author{
Wolters Kluwer, Lippincott Williams \& Wilkins, Philadelphia, Baltimore, \\ New York, London, Buenos Aires, Hong Kong, Sydney, Tokyo, 2007, 944 pp, \\ num. Ill, \$ 9.79, ISBN-13: 978-0-7817-7068-2, ISBN-10: 0-7817-7068-8
}

\section{Pierre Kehr}

Received: 16 August 2009 / Accepted: 18 August 2009 / Published online: 2 September 2009

(C) Springer-Verlag 2009

This work was conceived as a base of questions intended for the students in surgery. It is divided into four sections: overview and background surgical information, general surgery, subspeciality surgery, and power reviews and microvignettes. The topics approached are very exhaustive, in the "good manners" to the customs and habits of the perfect trainee of surgery, while passing by the acronyms to retain the courses and obviously traditional questions relating to the surgical specialities.

We particularly recommend the recommendations to the trainees that one would believe left another time or the handbooks perfect US-Marines (chapter I: sleep deprivation and the perfect trainee: "I am hardcore and I need No sleep", "Yes Sir").

This work is undoubtedly primarily intended to the American residents.

No funds were received in support of this study.

Laurent Balabaud Paris
P. Kehr $(\square)$

Strasbourg, France

e-mail: kehrpier@aol.com 